Research Article:

\title{
A Mouse Model of Acute and Delayed Complications of Sulfur Mustard Analogue, 2-Chloroethyl Ethyl Sulfide
}

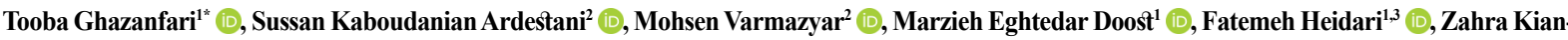 \\ mehr $^{4}$ (D), Reza Gharebaghi ${ }^{1}$, Reza Sedaghat ${ }^{5}$ (D), Hasan Ghasemi ${ }^{6}$ (D), Mohammad Mehdi Naghizadeh ${ }^{7}$, Marjan Heshmati ${ }^{5}$ (D), Mohammad Reza \\ Vaez-Mahdavi $^{8}$ (D), Soghrat Faghihzadeh ${ }^{9}$ \\ 1. Immunoregulation Research Center, Shahed University, Tehran, Iran. \\ 2. Institute of Biochemistry and Biophysics, University of Tehran, Tehran, Iran. \\ 3. Department of Ophthalmology, School of Medicine, Shahid Beheshti University of Medical Sciences, Tehran, Iran. \\ 4. Department of Biology, Faculty of Sciences, North Tehran Branch, Islamic Azad University, Tehran, Iran \\ 5. Department of Anatomy Tissue and Pathology, School of Medicine, Shahed University, Tehran, Iran. \\ 6. Department of Ophthalmology, Shahed University, Tehran, Iran. \\ 7. Department of Social Medicine, School of Medicine, Fasa University of Medical Sciences, Fasa, Iran. \\ 8. Department of Physiology, School of Medicine, Shahed University, Tehran, Iran. \\ 9. Department of Biostatistics and Epidemiology, Faculty of Medicine, Zanjan University of Medical Sciences, Zanjan, Iran.
}

\begin{tabular}{|l|l}
$\begin{array}{c}\text { Use yourdevice toscan } \\
\text { and read the artice online }\end{array}$ & $\begin{array}{l}\text { Citation Ghazanfari T, Kaboudanian Ardestani S, Varmazyar M, Eghtedar Doost M, Heidari F, Kianmehr Z, et al. A Mouse } \\
\text { Model of Acute and Delayed Complications of Sulfur Mustard Analogue, 2-Chloroethyl Ethyl Sulfide. Immunoregulation. } \\
\text { 2019; 2(1):9-24. http://dx.doi.org/10.32598/Immunoregulation.1.3.127 }\end{array}$ \\
dol http://dx.doi.org/10.32598/Immunoregulation.1.3.127
\end{tabular}

\section{(1) \$)}

Article info:

Received: 05 Mar 2018

Accepted: 13 Jul 2018

Available Online: 01 July 2019

\begin{abstract}
A B S T RA C T
Background: Numerous studies have been conducted on humans, animals, and cell cultures exposed to Sulfur Mustard (SM). However, the precise mechanism and cause or long-term pattern of SM injuries are not well defined. There is no protocol available for treating people with severe eye, lung, and skin ailments. The current study aimed to develop an animal model of the acute and delayed complications of SM exposure.
\end{abstract}

Materials and Methods: Two strains of mice (BALB/c and C57BL/6), 6-8 weeks old at the onset of the study, were exposed to 2-Chloroethyl Ethyl Sulfide (CEES) (1-200 mg/kg) and solvents (Tyrode's solution, Polyethylene Glycol 300, herbal oil) for a duration of 12 hours to 7 months. The administration route was Intraperitoneal (IP) injection. The mortality rate, signs, and apparent side effects were explored. At the end of the study, the mice's lung, liver, and spleen tissues were extracted and fixed for future histopathological assessments.

Results: Tyrode's solution and Polyethylene Glycol 300 solvents were not appropriate for the present research. Pathological features observed in BALB/c mice were better than the C57BL/6 mice. Overall, $10 \mathrm{mg} / \mathrm{kg}$ CEES was the most suitable dose, because it had the least mortality rate and demonstrated the most pathological findings, such as the infiltration of inflammatory cells and proliferation of fibroblasts and fibrotic tissue in the lung. Five months after the CEES administration, the delayed phase complications were studied.

Conclusion: The IP injection of $10 \mathrm{mg} / \mathrm{kg}$ CEES to BALB/c mice imitates short- and long-term complications of SM exposure in humans. This model is useful for preventing and treating SM exposure.

\section{Keywords:}

Mice model, Sulfur Ethyl Sulfide, Short-term complications, Long-term complications

\section{* Corresponding Author:}

Tooba Ghazanfari, PhD.

Address: Immunoregulation Research Center, Shahed University, Tehran, Iran.

Phone: +98 (21) 66418216

E-mail: tghazanfari@yahoo.com 


\section{Introduction}

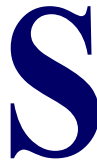

ulfur Mustard [bis(2-chloroethyl) sulfide] (SM), also known as mustard gas, is a highly toxic blistering agent that causes severe debilitating injuries to the lungs, eyes, skin, and other organs [1]. The commercial analog of SM, called half mustard, 2-Chloroethyl Ethyl Sulfide (CEES), has less terminal chlorine content than MS. Thus, its toxicity is less than SM, but its DNA alkalization and vesicatory properties are similar to mustard gas. Therefore, more investigation is underway to find the molecular mechanism of SM and the treatment of its ailments [2]. During the Iraq-Iran war (1980-1988), Iraqi forces used chemical weapons against both civilians and military personnel in Iranian border towns [1].

According to the World Health Organization, chemical inhalation poisoning symptoms include sneezing, rhinorrhea, tearing, nasal epistaxis, coughing, chest pain, dysarthria, and tachypnea. After almost two years, delayed SM exposure complications manifest as pulmonary, ocular, dermatological, and central nervous system disorders [1]. The risk of human exposure to SM as a chemical weapon or in terrorist attacks is rising for many reasons, such as its low preparation cost, no need for advanced knowledge on this particular subject, rudimentary technology and equipment, storage feasibility, and so on [3].

Many animal model studies have investigated shortand medium-term complications associated with SM poisoning, but not the long-term ones, for example, 24 hours to 7 days [4] or 48 hours to 28 days [5] and up to 60 days [5]. Researchers also explored its effects on special target organs, such as studying hairless mice to determine the dermatological side effects of SM [6], and the direct exposure of rabbits' eyes to SM for the evaluation of its local effects on animals' eyes [7], or its direct exposure on the respiratory system [8]. Few studies have been conducted on the long-term animal model of SM [9]. Therefore, the majority of animal studies lacked a design for an animal model of SM exposure.

Furthermore, many human studies have evaluated the short- and long-term effects of SM on different organs and tried to determine its pathophysiological and delayed molecular mechanism. However, the precise molecular mechanism of delayed complications of SM in humans is unclear, and there are no appropriate prevention or treatment approaches available [10]. Because of the limitations of human studies, creating an animal model and examining the effects of SM on animals is the only appropriate solution.
Therefore, the present study is the first to develop a suitable and acceptable mouse model for SM. Therefore, we evaluated different solvents and dosages of CEES in two types of mice strains. The present study evaluated the systemic effect of CEES on different organs. Thus, we conducted Intraperitoneal (IP) injection route of exposure, instead of local involvement routes such as intratracheal or direct inhalation.

We also evaluated the incidence of acute phase symptoms, including diffuse alveolar damage and the lung and liver tissue congestion. Our long-term investigation also included goblet cells hyperplasia/metaplasia, and parenchymal inflammation/fibrosis in the lung; oval cell proliferation and bile duct hyperplasia in the liver, and white pulp hypocellularity in the spleen. In addition, mortality rate, signs, symptoms, and animals' weights were studied.

\section{Materials and Methods}

The current study aimed to develop short- and longterm contamination models with a single dose of CEES Thus, we conducted the study in different steps, to use the results of each step for designing the next one.

\section{Chloroethyl Ethyl Sulfide, Sulfur Mustard ana- logue, and laboratory animals}

CEES with $98 \%$ purity was purchased (Sigma Company, St. Louis, USA) and maintained at $4^{\circ} \mathrm{C}$. All animals were obtained from the Pasteur Institute of Iran and the standard housing conditions for laboratory animals were observed (e.g. free access to food and water, 12:12 $\mathrm{h}$ light-dark cycle, the temperature of $22-25^{\circ} \mathrm{C}$ ). The Animal Care Committee approved all experimental protocols (IR.Shahed.REC.1394.79). The density of CEES was taken into consideration $(1.07 \mathrm{~g} / \mathrm{mL})$ and the proper amount was dissolved in different solvents, and then 100 $\mu \mathrm{L}$ was Intraperitoneally injected. The different steps of this study are presented in details in Table 1. The control group received the befit solvent. At the time of injections, all the personal and environmental protection protocols, set by the CEES manufacturer were observed, including the use of a chemical mask, gloves, dressing gowns, and the laminar flow hood supplied with coal filter.

\section{Determining the mortality rate}

In order to determine the Lethal Dose 50 (LD50), the animals received different dosages of CEES and were studied for 14 days. The mortality rate for each group was observed. The percentage of mortality for each 
Table 1. The details of the different steps of the study

\begin{tabular}{|c|c|c|c|c|c|c|}
\hline Steps & The Aim of the Step & CEES Dose $(\mathrm{mg} / \mathrm{kg})$ & Solvent & Mouse Strains & No./Group & Study Duration \\
\hline 1 & $\begin{array}{l}\text { Determination of LD50 } \\
\text { in different solvents } \\
\text { and mice }\end{array}$ & $\begin{array}{c}1,5,10,20,30,40,50,100 \text { and } \\
200 \mathrm{mg} / \mathrm{kg}\end{array}$ & $\begin{array}{c}\text { Tyrode's solution, } \\
\text { PEG300*, herbal } \\
\text { oil }\end{array}$ & $\begin{array}{l}\mathrm{BALB} / \mathrm{c} 1 \\
\mathrm{C} 57 \mathrm{BL} / 62\end{array}$ & 4 & 6 months \\
\hline 2 & $\begin{array}{c}\text { Determination of } \\
\text { the exact dose of the } \\
\text { LD50 and appropriate } \\
\text { solvent }\end{array}$ & $\begin{array}{c}10,12.5,15,17.5,20,22.5,27.5 \\
\text { and } 30 \mathrm{mg} / \mathrm{kg}\end{array}$ & $\begin{array}{l}\text { PEG300, herbal } \\
\text { oil }\end{array}$ & $\begin{array}{l}\mathrm{BALB} / \mathrm{C} \\
\mathrm{C} 57 \mathrm{BL} / 6\end{array}$ & 4 & 6 months \\
\hline 3 & $\begin{array}{l}\text { Evaluation of the short- } \\
\text { and long-term effects } \\
\text { of CEES }\end{array}$ & $10 \mathrm{mg} / \mathrm{kg}$ & Herbal oil & $\mathrm{BALB} / \mathrm{c}$ & 10 & $\begin{array}{c}12 \text { hours; } 24 \\
\text { hours; } 1,2 \text { and } \\
4 \text { weeks, as well } \\
\text { as, } 2,4,6 \text {, and } 7 \\
\text { months }\end{array}$ \\
\hline
\end{tabular}

group was calculated by the number of dead mice/the number of mice in that group.

\section{Monitoring of animals}

During the study, bleeding, movement, restlessness, and apparent side effects such as hair loss, blisters, and rashes were recorded in animals of different groups.

\section{Animals' weight and organ indices}

The animals were weighed on the day of the injection (primary weight), and on the day of killing (secondary weight). After the killing, their organs, including the liver, lung, and spleen were removed and weighed, and the index of tissue was calculated by the tissue weight/ mouse weight formula.

\section{Histopathology}

At the end of each step, the organs (liver, lung, and spleen) were carefully separated and put in the fixator ( $10 \%$ formalin in physiologic serum), for future histopathological assessments. Because of many variables (different administration times, doses, etc.), we scored pathological outcomes under various assumption as well as the lowest dose that caused complication had higher importance and consequently higher weight also a higher dose had less weight, e.g. a dose of $1 \mathrm{mg} / \mathrm{kg}$ had a weight 6 , dose $2 \mathrm{mg} / \mathrm{kg}$ had a weight 5.83 , dose $5 \mathrm{mg} / \mathrm{kg}$ had weight 5.31 , and finally dose 30 had a weight of 1 . Then, the evaluation time was graded according to the main study objectives, i.e. assessing long-term complications.

Each pathological symptom that occurred at a later time received higher scores (corresponding to the number of times). For example, one week was allocated a weight of 0.5 , one month, a weight of 1 , and 7 months a weight of 7. Ultimately, the occurrence of pathological complication was multiplied by the dosages and time scores. Moreover, we reported dose- and time-dependent pathological complications in a chart.

\section{Statistical analysis}

The mortality rates of each group were calculated by the number of dead mice/the number of mice in that group. The primary and secondary weights of mice were demonstrated as Mean $\pm \mathrm{SD}$. The index of tissues was also determined (tissue weight/mouse weight). Histopathological evaluations were graded by a pathologist and the relevant details are presented in the histopathology section. The histopathology histogram was drawn by R software version 3.5.0 [11]. The t-test and one way Analysis of Variance (ANOVA) were used for betweengroup comparisons in Excel and SPSS. $\mathrm{P} \leq 0.05$ was considered statistically significant.

\section{Results}

Step 1

The mortality rate of mice receiving different dosages of CEES mixed with various solvents are shown in Figure 1. Figure 2 shows the primary and secondary weight changes of all groups. Only BALB/c mice weights that received a $10 \mathrm{mg} / \mathrm{kg}$ of CEES with herbal oil were significantly reduced, compared to the control group ( $\mathrm{P}<0.0011)$. The weight indices of lung, liver, and spleen of mice that received different doses of CEES with various solvents are shown in Figures 3, 4, and 5.

In BALB/c mice receiving CEES in Polyethylene Glycol 300 (PEG300) solvent, the most frequent pathological complications were hemorrhaging in the lung tissue and congestion in liver tissue. In $\mathrm{BALB} / \mathrm{c}$ mice receiving 


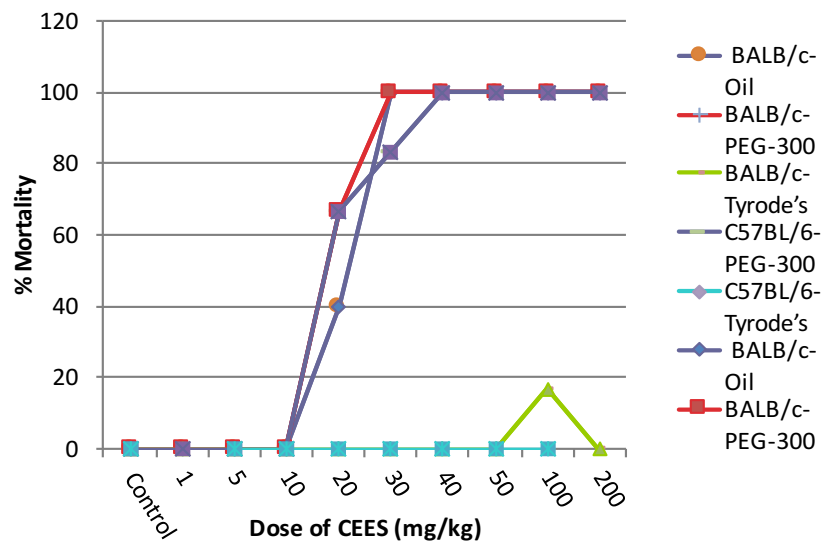

ImúnoRegulation

Figure 1. The mortality rates of BALB/c and C57BL/ 6 mice receiving various analog dosages $(1-200 \mathrm{mg} / \mathrm{kg})$ with PEG300 and herbal oil solvents

*CEES with solvent Tyrode's did not cause death in any type of mice.

CEES in herbal oil solvent, the most common adverse effects of lung and liver were emphysema and congestion, respectively. In C57BL/6 mice receiving CEES in PEG300 solvent, congestion and hyperemia in the lung tissue and congestion in liver tissue were found. Pathological observations are shown in Figures 6 and 7.

\section{Results of step 1}

Tyrode's solvent was not suitable for determining LD50 and was excluded from the study. The LD50 was expressed in the doses of $10-30 \mathrm{mg} / \mathrm{kg}$ of CEES in PEG300 or herbal oil solvents.

\section{Step 2}

Mortality rate assessments revealed that the highest mortality rates belonged to doses above $15 \mathrm{mg} / \mathrm{kg}$. The mortality rates in mice receiving different doses of CEES are shown in Figure 8. Figure 9 shows the weight changes in respect of the CEES among herbal oil solvent recipients after 6 months.

The most frequently observed pathological findings in the BALB/c mice livers receiving different CEES doses in PEG300 solvent were hepatocytes atrophy. Additionally, there was liver congestion in the same type of

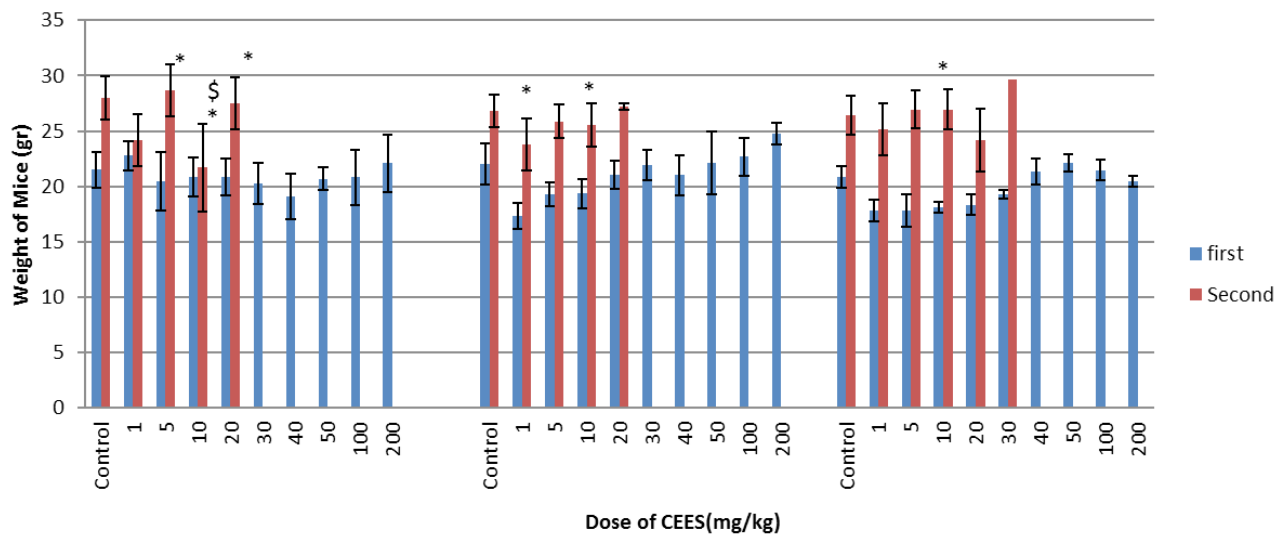

Balb/C-Oi

Balb/C-PEG300

C57/B-PEG300

InvovoRegcLution

Figure 2. Primary and secondary weights of BALB/c and C57BL/ 6 mice receiving different doses of CEES (1-200 mg/kg), with PEG300 and herbal oil solvents, at 6 months after CEES injection

* Significant statistical difference of primary and secondary weights in each group. \$ Statistical difference between the secondary weight of the CEES recipient group and the control group. $\mathrm{P}<0.05$ was considered as statistically significant. \# The CEES recipient group with Tyrode's solvent was excluded due to the lack of mortality that could determine an LD50. 


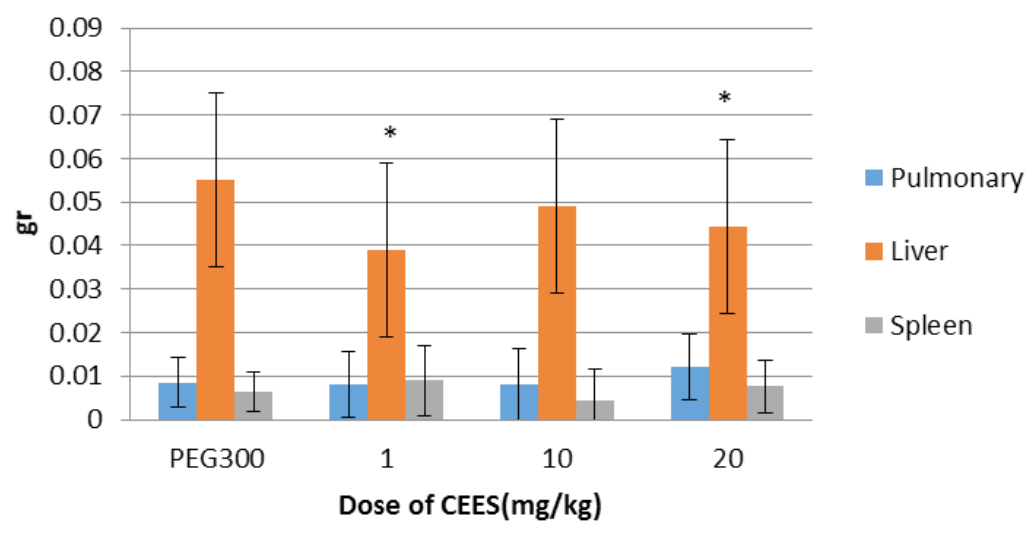

IMMUNoReGULATION

Figure 3. Weight indices of the lung, liver, and spleen in BALB/c mice receiving different doses of CEES (1-200 mg/ $\mathrm{kg})$ in PEG300 solvent at 6 months after CEES injection

* There was a significant difference between the trial and control groups. $\mathrm{P}<0.05$ was considered as statistically significant.

mice receiving CEES in herbal oil solvent. In the lung of BALB/c mice receiving CEES with PEG300 solvent, congestion, and hyperemia, and subsequently, the hyperplasia of the bronchial epithelium was observed. However, in the same type of mice receiving CEES in herbal oil solvent, congestion, hyperemia, and emphysema in the lung tissues were observed. In the $\mathrm{C} 57 \mathrm{BL} / 6$ mice, milder complications, including hyperplasia of the bronchial epithelium and smooth muscle hypertrophy were observed. Figures 10, 11 and 12 illustrate the pathological changes observed in the lung and liver tissues of mice receiving different doses of CEES in various solvents.

\section{Results of step 2}

The mortality rate in the control group, and especially physiological and pathological findings suggest that
PEG300 solvent and C57BL/6 mice are not suitable for the purpose of this study. The LD50 was determined with $17.5 \mathrm{mg} / \mathrm{kg}$ dose of CEES in herbal oil. However, in 10 $\mathrm{mg} / \mathrm{kg}$ dose, which had the lowest mortality rate, weight loss, and pathological complications were selected to be the original model and received final approval.

Step 3: The main step

\section{Monitoring signs}

Poor mobility and hair loss were observed at the end of the fourth month after the injection. Figure 13 shows the phenotypic differences of the mouse receiving $10 \mathrm{mg} / \mathrm{kg}$ dose and the mouse receiving solvent at 6 months after contamination.

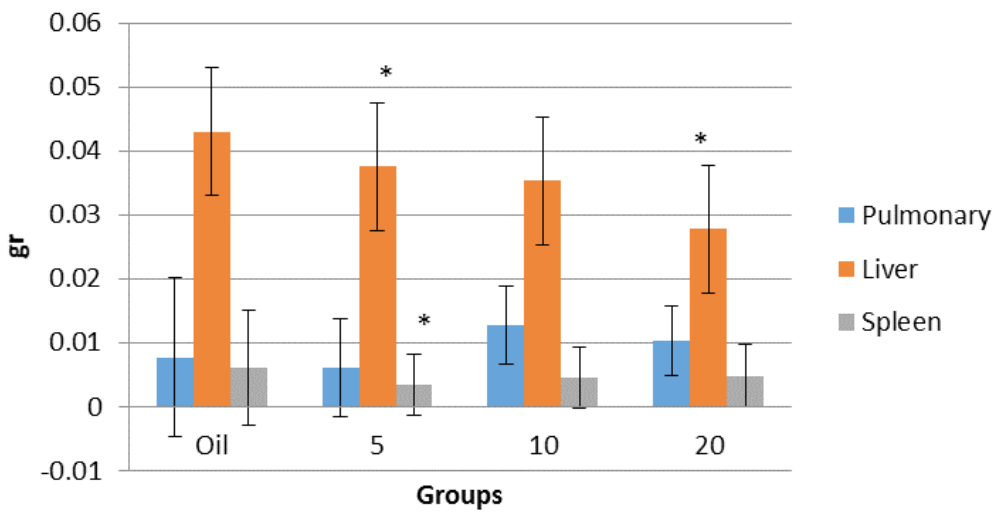

IMmunoRegulation

Figure 4. Weight indices of the lung, liver, and spleen in BALB/c mice receiving different doses of CEES (1-200 mg/ kg), with herbal oil solvent at 6 months after CEES injection

* There was a significant difference between the trial and control groups. $\mathrm{P}<0.05$ was considered statistically significant. 


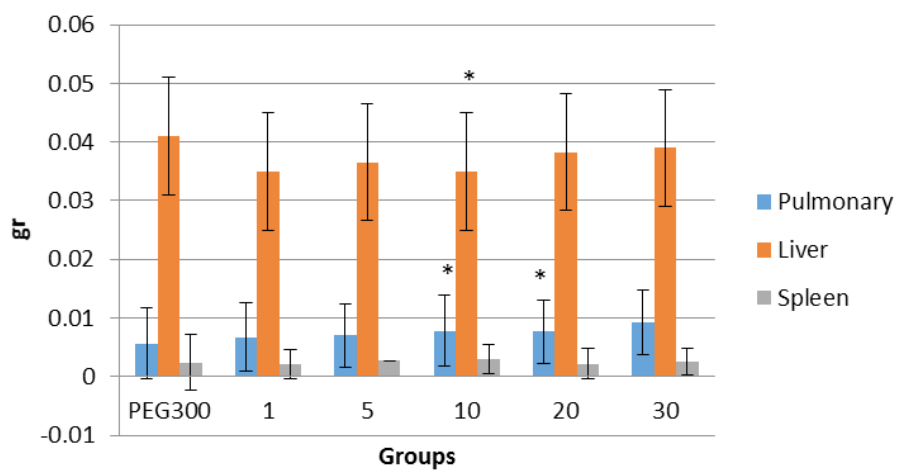

IMMUNoRegulation

Figure 5. Weight indices of the lung, liver, and spleen in C57BL/ 6 mice receiving different doses of CEES (1-200 mg/kg), with PEG300 solvent at 6 months after CEES injection

* There was a significant difference between the trial and control groups. $\mathrm{P}<0.05$ was considered as statistically significant.

Changes in body weight and weight index of animals

The weight changes of the studied animals are shown in Figure 14 at 12 hours up to 7 months after CEES exposure interval. The secondary weight of approximately all animals increased. This increase was significant in the control group and recipient of $10 \mathrm{mg} / \mathrm{kg}$ CEES over 4 months $(\mathrm{P}<0.00029, \mathrm{P}<0.00063, \mathrm{P}<0.0085, \mathrm{P}<0.0011$ and $\mathrm{P}<0.059$, respectively for the CEES recipients at 3-month, 4-month, and 5-month intervals, and its respective control group, as well as the control group measurements at 6 months). However, the control group's weight gain was higher than the CEES group. The differences between the secondary weight of the control and CEES groups are significant in all groups at one-week

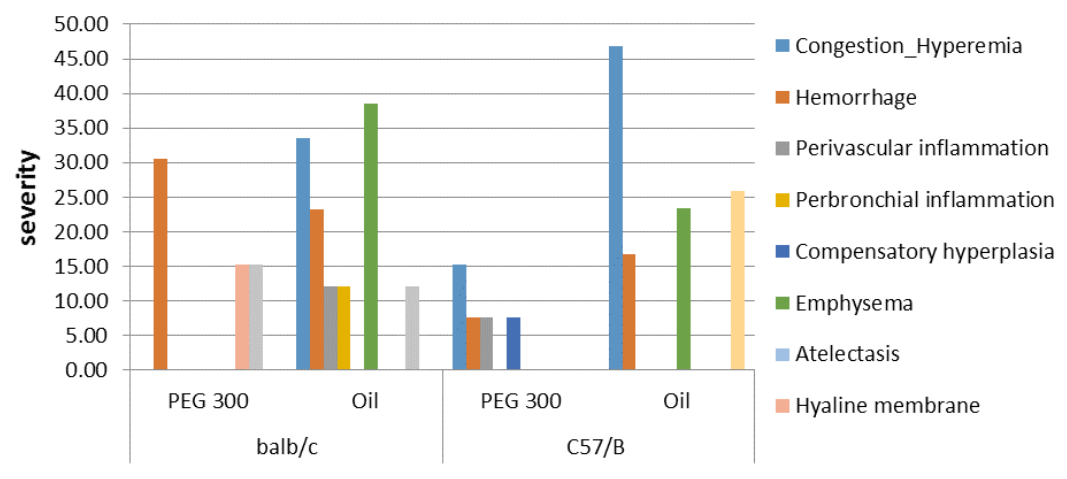

IMMUNoReGULATION

Figure 6. The pathological findings of lung tissue of BALB/c and C57BL/ 6 mice receiving different CEES doses in PEG300 and herbal oil solvents at 6 months after CEES injection

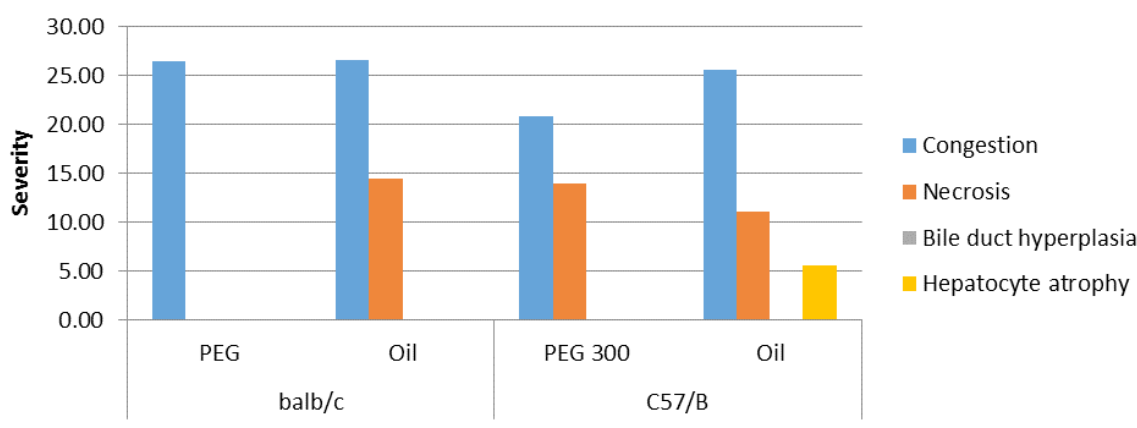

IMMUnoReguLATION

Figure 7. The pathological findings of liver tissue of BALB/c and C57BL/ 6 mice receiving different CEES doses in PEG300 and herbal oil solvents at 6 months after CEES injection 


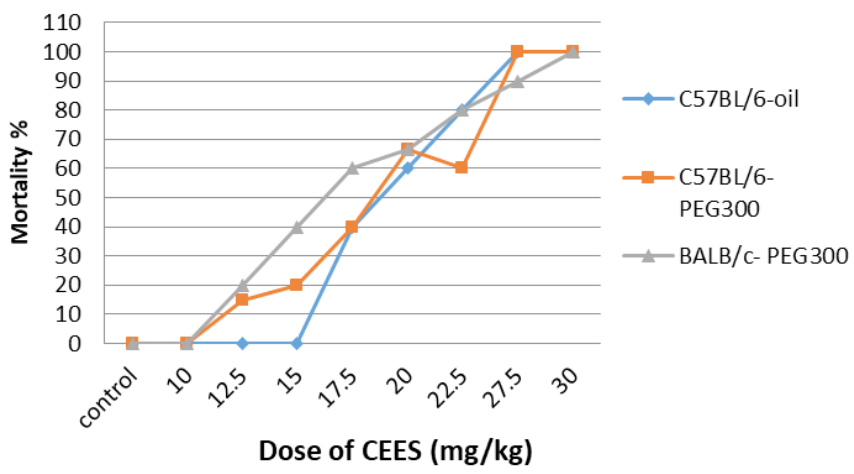

ImMunoRegutation

Figure 8. The mortality rates in BALB/c and C57BL/ 6 mice receiving different CEES doses (10-30 mg/kg) in PEG300 and herbal oil solvents

interval $(\mathrm{P}<0.0018, \mathrm{P}<0.00015, \mathrm{P}<0.03$, and $\mathrm{P}<0.00063$ respectively for 1-week, 1-month, 2-month, 3-month, and 5-month intervals). However, CEES reduces the animal's natural growth process.

\section{Pathological findings}

The histopathological examination of lung, liver, and spleen of mice was performed. In this step, the pathological complications and their severity were recorded. The rates below $25 \%, 25-50 \%, 50-75 \%$, and above $75 \%$ of the studied area were graded 1,2, 3, and 4, respectively. These scores were then considered for the type of observed pathology. The obtained results of this section are shown in Figure 15. As per Figure 15, when moving from the left side of the graph to right, the long-term, as well as late phase pathological complications, are evident.

Pathological changes observed in the lung tissues were goblet cells hyperplasia/metaplasia, perivascular inflammation, and peribronchial inflammation. The liver tissues changes comprised a mixture of lobular pattern, congestion, and bile duct hyperplasia. Additionally, in the spleen tissue, we detected a reduction in the volume of red pulp, which is a long-term complication following CEES exposure. However, complications such as emphysema, atelectasis, parenchymal inflammation/ fibrosis, and congestion/hyperemia in the lung tissues;

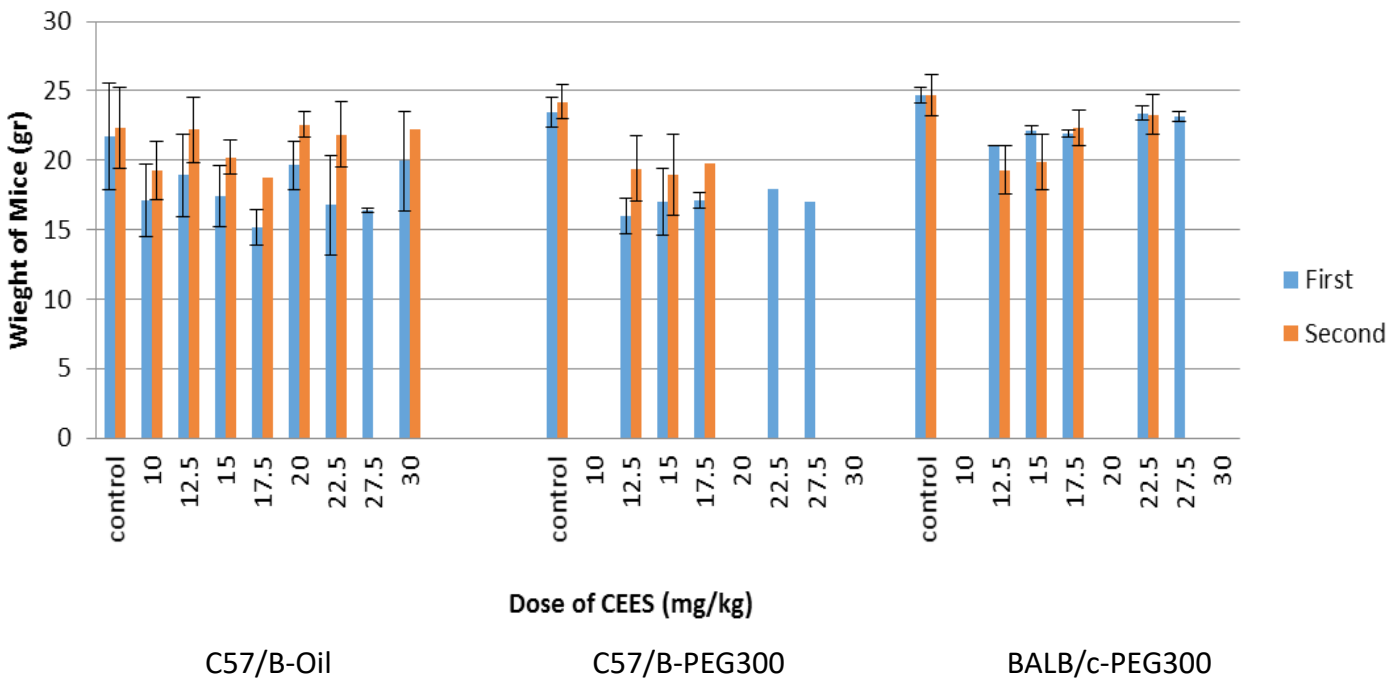

IMMUNoREGULATIOS

Figure 9. Primary and secondary weights of BALB/c and C57BL/ 6 mice receiving different CEES doses $(10-30 \mathrm{mg} / \mathrm{kg})$ in PEG300 and herbal oil solvents at 6 months after CEES injection

* Statistically significant differences between the primary and secondary weights in each group. \$ Statistical differences between the secondary weights of CEES recipient and the control groups. $\mathrm{P}<0.05$ was considered as statistically significant. 
A

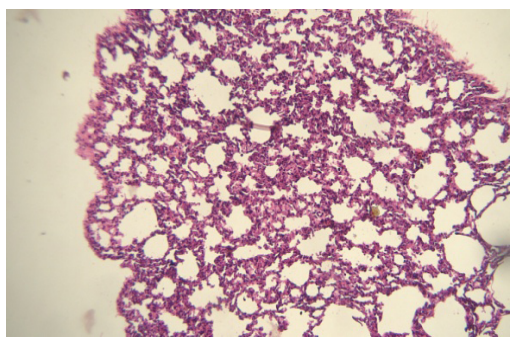

B

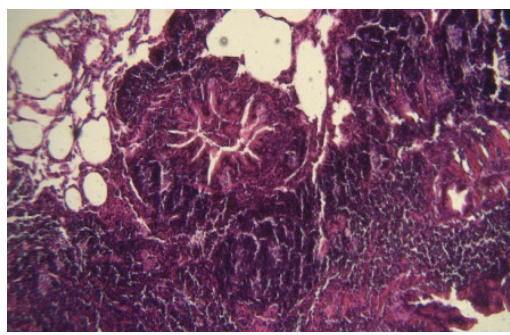

C

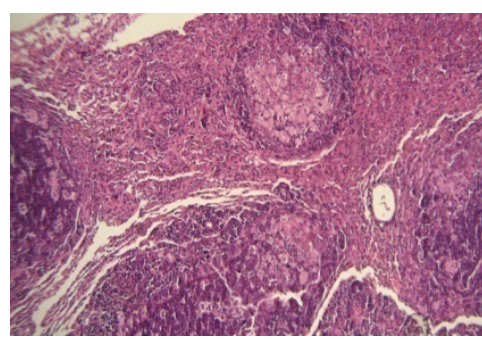

ImvunoRegulation

Figure 10. Pathological complications observed in the lung tissue of mice receiving $10 \mathrm{mg} / \mathrm{kg}$ CEES 6 months after contamination (A) Lung tissue of the control mice (H\&E, 100x); (B) interstitial pneumonia with notable peribronchiolitis, perivasculitis, and evidence of hyperplasia of bronchial epithelium was detected (H\&E, 100x); and (C) Severe interstitial pneumonia with the accumulation of foamy macrophages were detected (H\&E, 100×).

granulovacuolar degeneration and necrosis in the liver; and congestion/hemorrhage in the spleen tissues occurred in the shortest time, i.e. after 12 hours of injection and continued until the end of the seventh month.

These are the constant complication of CEES exposure and are probably not time-dependent. Some complica- tions occurred within two weeks after exposure but resolved within 7 months. These complications included megakaryocyte activation in the spleen, edema, and hemorrhage in the lung and hemorrhage and hyperactivation of Kupffer cells in the liver. There were no white pulp hypocellularity in the spleen, or hepatocyte atrophy and parenchymal hepatitis in the liver, in the acute phase

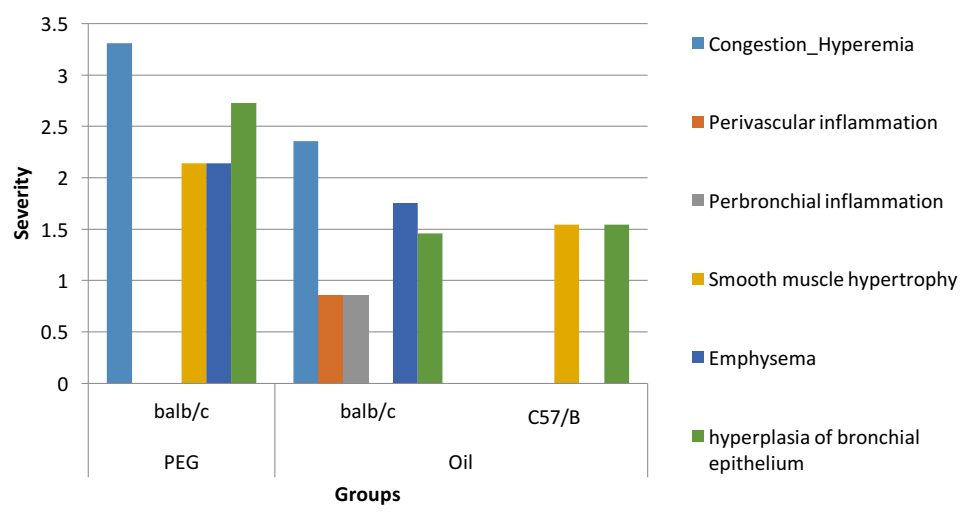

IMMUNoRecULATION

Figure 11. The pathological findings of lung tissues of BALB/c and C57BL/6 mice receiving different CEES doses in PEG300 and herbal oil solvents at 6 months after CEES injection

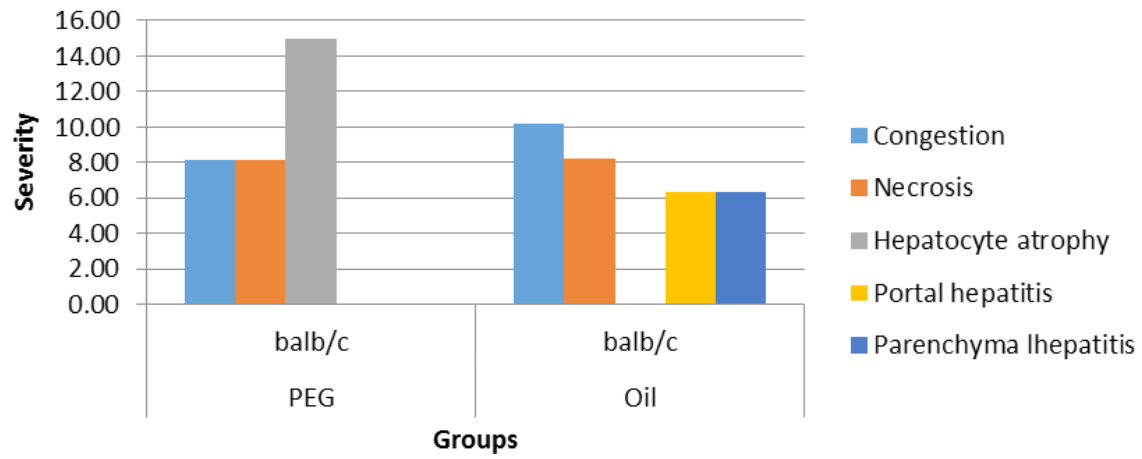

IMmunoRegulation

Figure 12. The pathological findings of liver tissues of BALB/c mice receiving different CEES doses in PEG300 and herbal oil solvents at 6 months after CEES injection 


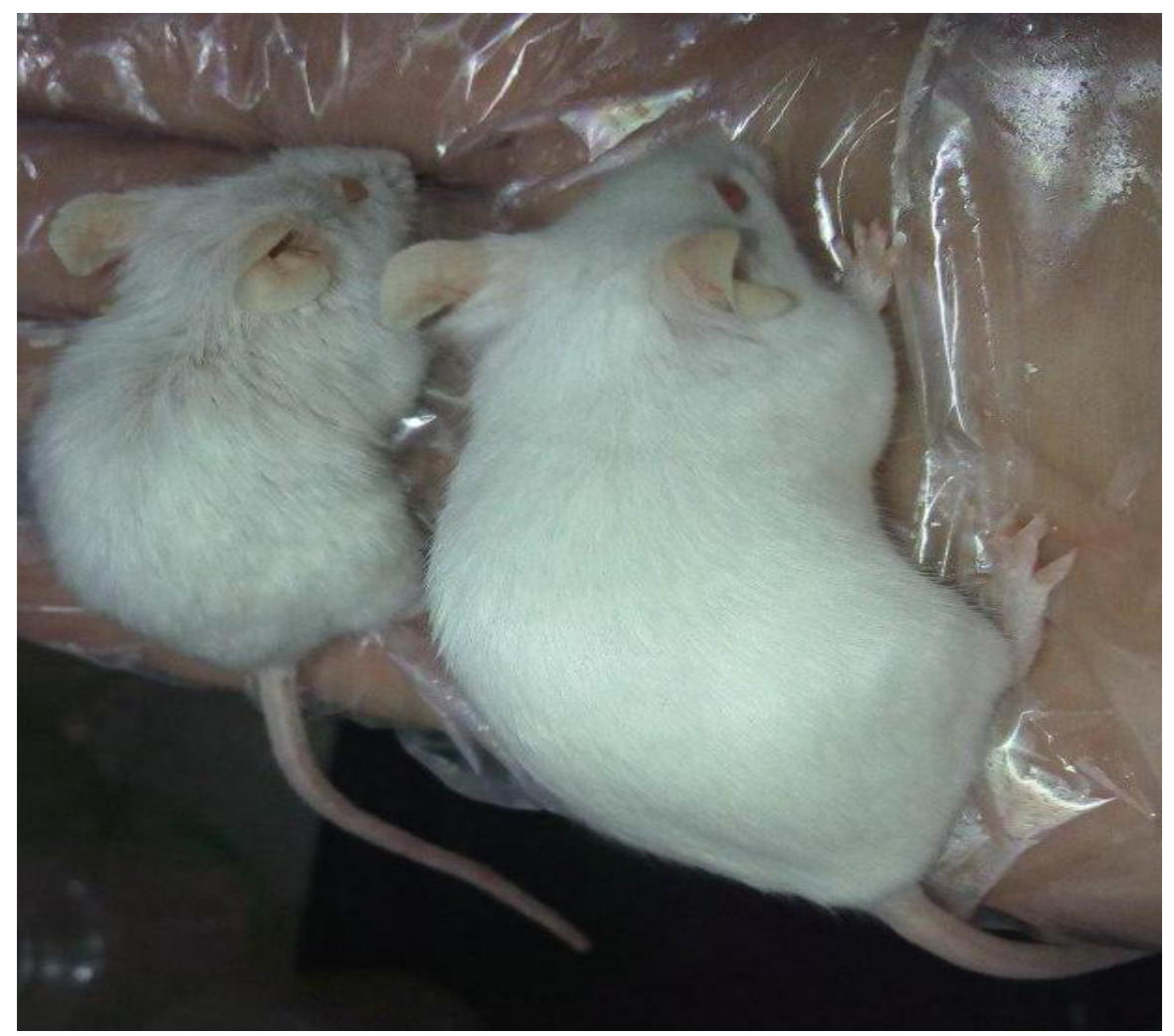

IMMUNoREGULATION

Figure 13. The control mouse (right) and $10 \mathrm{mg} / \mathrm{kg}$ CESS recipient mouse in the CEES group (left) at 6 months after contamination Severe weight and hair loss are apparent in the CEES-receiving mouse.

of exposure (less than 2 months). It could be because these complications would develop over time and would not appear until the end of this study.

The color intensity change from yellow to red indicates an increase in the severity of the complication. The $\mathrm{x}$ axis represents the time after the injection of CEES. The right axis represents the type of pathology observed in the Lung tissues (LU), Liver (LV) and Spleen (SP). On the left axis, the concurrence probability of two pathologies in one group is shown. By moving from the left to the right side of the chart, the long-term complications become evident. The complications noted in area 1 , indicate those developed 12 hours post-injection and remained within 7 months so they are not time-dependent. There are present from the very short-time to long-term and delayed times. In areas 2 and 4, complications that do not occur in a short time after injection with acute complications are shown, but in time, the low severity (area 2), and high severity (area 4) complications occurred. Complications shown in area 3 are not present in acute and long time and are classified as delayed and long-term complications.
In Figures 16, 17, and 18, the microscopic view of the pathologic complications following contamination in liver, lung, and spleen of BALB/c mice that received $10 \mathrm{mg} / \mathrm{kg}$ CEES at different time points from 12 hours to 7 months are shown. In order to confirm the observed pathological complications, the lungs from the 6 and 7 months groups were prepared and stained with Masson's trichrome stain. The obtained results revealed mustard-induced fibrosis characterized by a patchy distribution in the lung parenchyma. Trichrome staining demonstrated the diffuse presence of collagen in the parenchyma, around vascular spaces and airways, interalveolar spaces, and perialveolar areas. Seven months after the exposure, the number of collagen fibers around the alveolus that formed supporting meshwork for the lung parenchyma were higher than the cases of 6 months post-exposure. In Figure 19, the trichrome staining of these samples is shown.

\section{Discussion}

The current study mainly aimed to create an animal model for SM exposure best resembled the conditions experienced by the people exposed to SM during the 


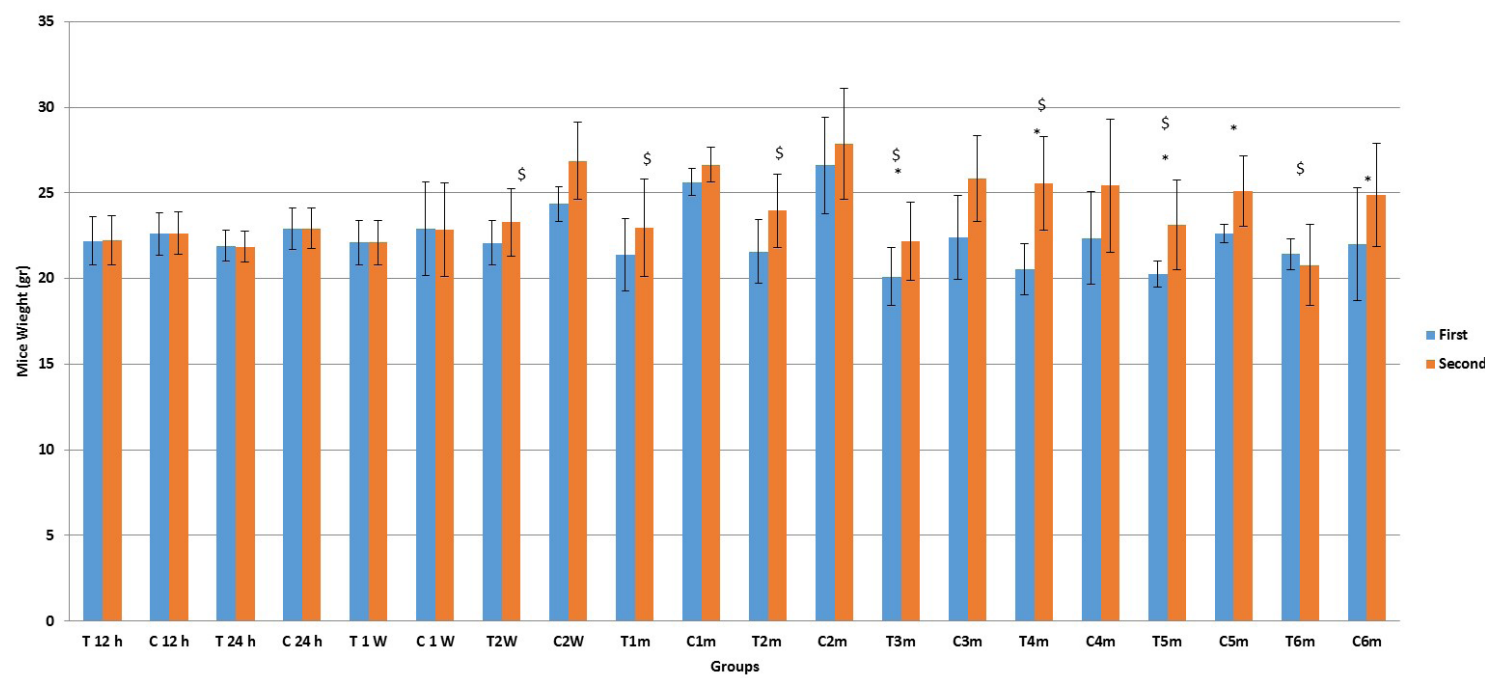

IMMUNoREGULATION

Figure 14. Primary and secondary weights of BALB/c mice receiving $10 \mathrm{mg} / \mathrm{kg}$ CEES with herbal oil solvent at different times after CEES injection

* Statistically significant differences of the primary and secondary weights in each group. \$ Statistically significant differences between the secondary weight of CEES recipient group and the control group. $\mathrm{P}<0.05$ was considered statistically significant.

Iraq-Iran war. The obtained data could be used to investigate the delayed and long-term complications of this toxic vesicant chemical warfare agent. Most animal studies investigated hyperacute and acute complications of SM. Very few studies examined its long-term local complications and on only one organ. In fact, no studies have ever created an animal model, and only briefly examined the effects of SM.
In the current study, the first step was to determine the appropriate dose for causing short- and long-term complications of CEES. We discovered the solvent-induced effects as well. By examining the three solvents used for CEES and identifying the advantages and disadvantages of each, the herbal oil solvent was selected. Because of a lack of mortality, Tyrode's solution, even in high dose, is not suitable to determine the LD50. According to prior studies, the water-based solvents, including Phosphate-

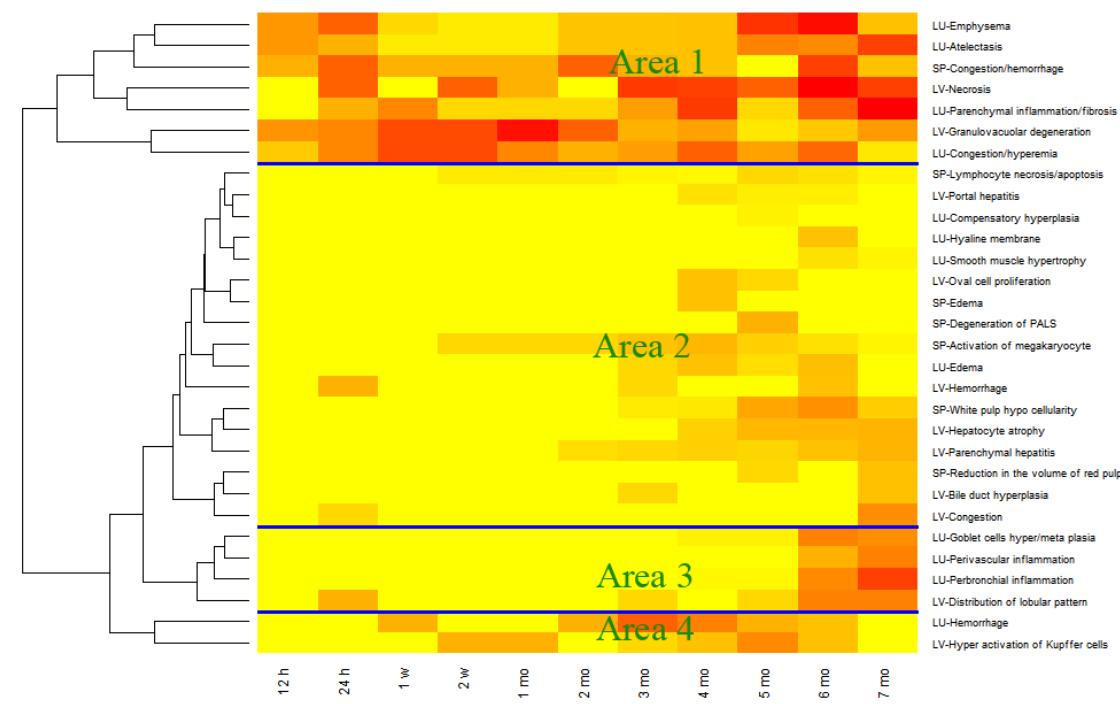

ImMunoRegulation

Figure 15. The pathological complications generated with $10 \mathrm{mg} / \mathrm{kg}$ CEES from 12 hours to 7 months after the injection 

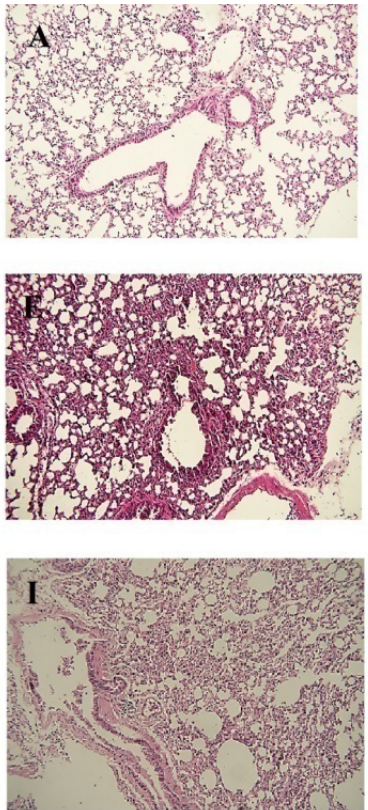
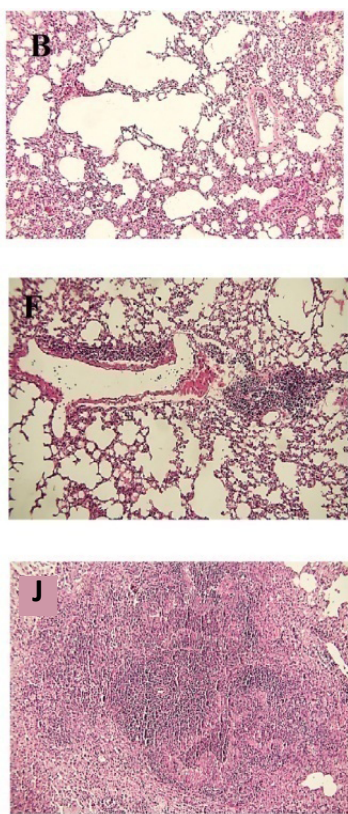
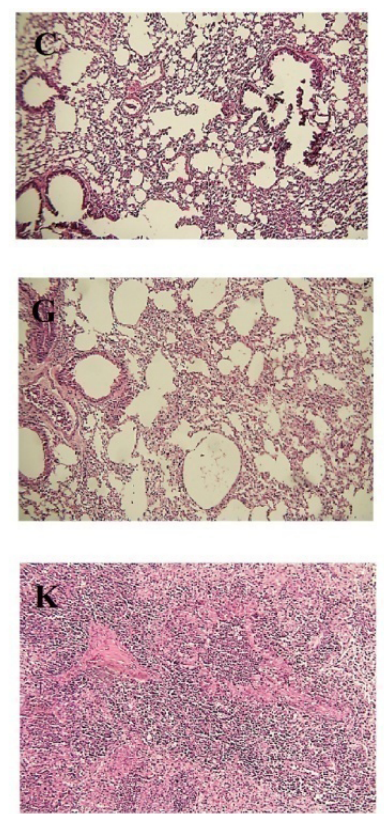
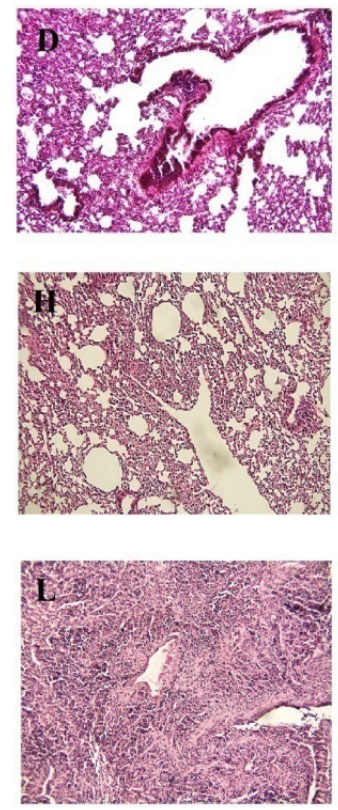

IMMUNoReGULATION

Figure 16. Pathologic complications observed in the lung tissue of mice receiving $10 \mathrm{mg} / \mathrm{kg}$ CEES at different time points from 12 hours to 7 months after contamination

(A) Note the normal appearance of the lung tissue in the control group; (B) 12 hours after receiving CEES; inflammatory cells with low to moderate severity in the interstitial tissue are evident. Also, emphysema and compression atelectasis are distinct; (C) 24 hours after receiving CEES; mild degree of interstitial pneumonia is observed; (D) 1 week after receiving CEES, note the moderate degree of mononuclear inflammatory cells infiltration in interstitial tissue as well as the relative hyperplasia of the epithelial tissue lining respiratory tract; (E) 2 weeks after receiving CEES; a mild to moderate interstitial pneumonia is detected; (F) 1 month after receiving CEES; the perivascular infiltration of mononuclear inflammatory cells are seen; (G) 2 months after receiving CEES; mild infiltration of mononuclear inflammatory cells in the interstitial tissue, mild hyperemia, and edema are observed; $(\mathrm{H}) 3$ months after receiving CEES; a mild interstitial pneumonia is apparent; (I) 4 months after receiving CEES; note the mild interstitial pneumonia, mild hyperemia and degenerative as well as necrotic changes of the bronchial wall; (J) 5 months after receiving CEES; note the diffuse infiltration of inflammatory cells with dominant lymphocytes and macrophages with foamy cytoplasm in parenchyma. Also note the presence of purulent exudation within the lumen of bronchiole, as well as the hyperplasia of the lining epithelium; (K) 6 months after receiving CEES; the extensive infiltration of inflammatory cells that are mostly lymphocytes and macrophages in the parenchymal tissue are evident; and (L) 7 months after receiving CEES; the vast majority of lung parenchyma tissue is occupied by inflammatory cells, mostly lymphocytes and macrophages, also note the proliferation of fibroblasts and fibrotic tissue in the interstitial zone (H\&E, 100×).

Buffered Saline (PBS) and Tyrode's solution, hydrolyze the CEES and do not have the expected effects of SM [12].

The metabolites following this degradation demonstrated different characteristics from the original material. They did not cause mortality in animals but have led to nonspecific or secondary pathologies, such as degeneration and necrosis in the liver, bronchopneumonia, and edema in the lung, and reduced size of white pulp in the spleen. In the case of PEG300, although the substance is toxic, it is widely used as a drug vehicle, and studies have reported that a single dose IP injection of PEG300 is associated with a very low mortality rate. However, its lethal dose causes death through progressive respiratory depression [13]. Our study suggested that although the CEES with PEG300 caused complications, it was not suitable because of the high mortality rate seen in the control group. Therefore, both Tyrode's and PEG300 solvents were excluded from the study.

In this study, a certain dose producing short- and long-term complications with the lowest mortality rate was considered as the optimal dose. At different steps, by injecting different doses of CEES from $1 \mathrm{mg} / \mathrm{kg}$ up to $200 \mathrm{mg} / \mathrm{kg}$, LD50 dose was determined and the optimal dose was established.

In 2006, Gautam et al. compared the effects of SM and CEES on mortality, oxidative stress, and DNA damage by different administration methods and different doses inducing acute complications, for a period of 1 to 7 days in Swiss female mice. They reported that the subcutaneous injection was correlated with the highest toxicity, as the Intraperitoneal LD50 injection of CEES was 17.7 $\mathrm{mg} / \mathrm{kg}$. The oral administration of the CEES for 7 days 
only reduced the animals' weight and other administration methods had no effect on their weight [14].

In the Gautam study, the LD50 of CEES was $17.7 \mathrm{mg} /$ $\mathrm{kg}$ for IP administration. Moreover, in the present study, the LD50 dose was between $15 \mathrm{mg} / \mathrm{kg}$ and $17 \mathrm{mg} / \mathrm{kg}$, which was highly similar to their result. In their study, the use of PEG300 did not cause death in the control group; however, in our study, the PEG300 administration in the control group caused a mortality rate of over $40 \%$. We obtained the same results at different steps and PEG300 was toxic in the control mice. In this study, according to the pathological complications and weight loss, $10 \mathrm{mg} / \mathrm{kg}$ of CEES was selected as the optimum dose. Also, no death was reported by this dose.

In terms of pathological complications, $10 \mathrm{mg} / \mathrm{kg}$ of the CEES dissolved in herbal oil in acute phase can cause congestion/hyperemia, hemorrhage in the lung, and granulovacuolar degeneration and congestion in the liver.
Furthermore, in the sub-acute phase, it leads to hepatocyte atrophy, lobular pattern distribution, and Kupffer cells hyperactivation in the liver. Additionally, it leads to hyaline membrane formation in the lung, red pulp volume reduction, megakaryocyte activation, PeriArteriolar Lymphoid Sheath (PALS) degeneration, and lymphocyte necrosis/ apoptosis in the spleen. In the long term, CESS causes smooth muscle hypertrophy, goblet cells hyperplasia/ metaplasia, perivascular inflammation, peribronchial inflammation, compensatory hyperplasia and parenchymal inflammation/fibrosis in the lung; oval cell proliferation and bile duct hyperplasia in the liver; and white pulp hypocellularity in the spleen. Edema in the spleen; emphysema and atelectasis in the lung; and parenchymal hepatitis, necrosis and portal hepatitis were time-independent and observed both in the acute and long phase.

The histological studies on animals exposed to SM indicated different short- and long-term complications on vital body tissues. In a study that investigated the short-
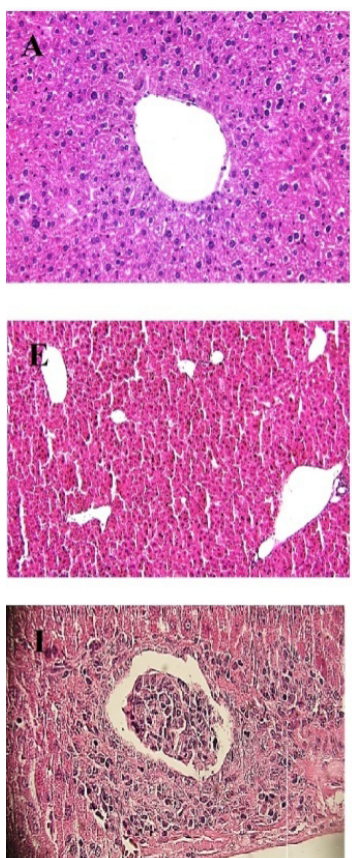
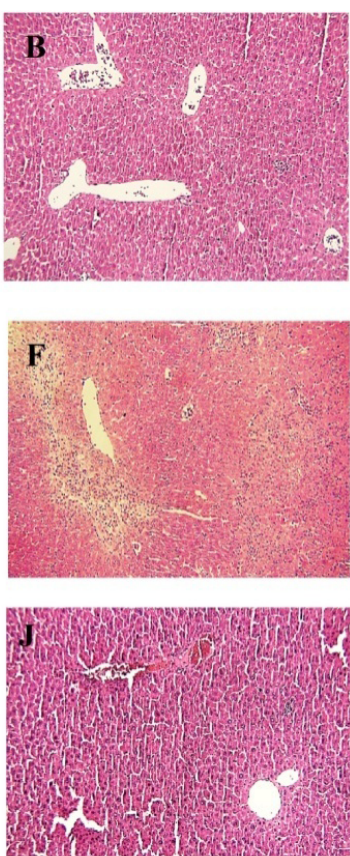
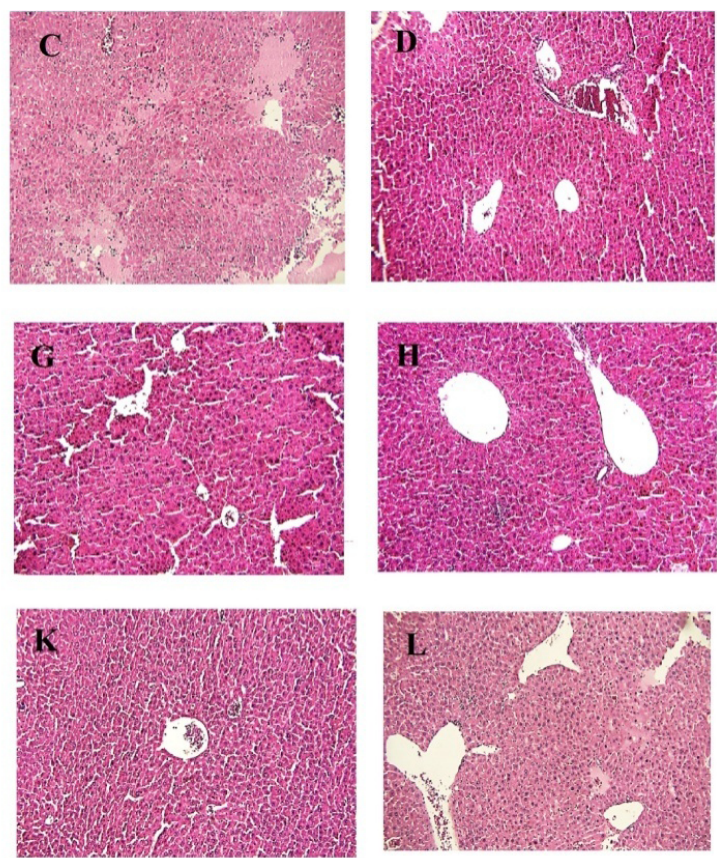

IMMUNoREGULATION

Figure 17. Pathologic complications observed in the liver tissue of the mice receiving $10 \mathrm{mg} / \mathrm{kg}$ CEES at different time points from 12 hours to 7 months after contamination

(A) Note the normal appearance of liver tissue in the control group; (B) 12 hours after receiving CEES; note to the normal appearance of liver tissue; (C) 24 hours after receiving CEES ; note the necrotic foci in the liver parenchyma and inflammatory cells infiltration in those areas; (D) 1 week after receiving CEES; note the hepatocytes necrosis (characterized by pyknotic nuclei), with diffuse and random distribution; (E) 2 weeks after receiving the CEES; the presence of nuclei with mild pyknotic changes and random distribution is evident; $(\mathrm{F}) 1$ month after receiving CEES; note necrotic foci with the infiltration of inflammatory cells in those areas; (G) 2 months after receiving CEES; a limited number of necrotic hepatocytes are evident with random distribution; (H) 3 months after receiving CEES; note the necrotic hepatocytes with random distribution; (I) 4 months after receiving CEES; note oval cell proliferation within the portal space; (J) 5 months after receiving CEES; note the mild hepatocyte atrophy and necrosis; (K) 6 months after receiving CEES; note the mild atrophy of hepatocytes; and (L) 7 months after receiving CEES; note the hyperplasia of Kupffer cells ( H\&E, 100×). 


\section{IMMUNoREGULATION}
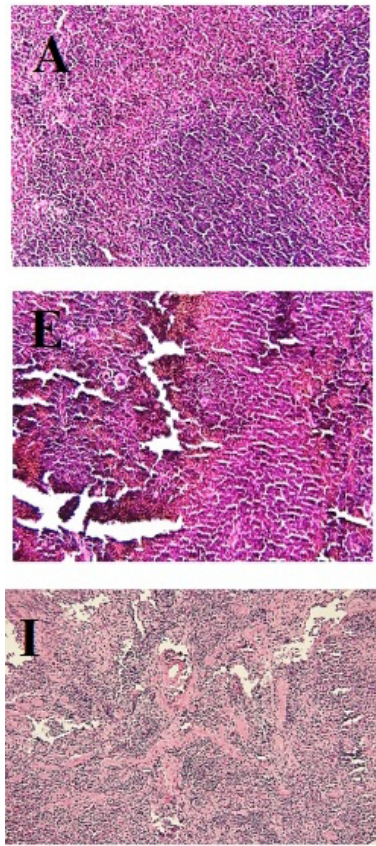
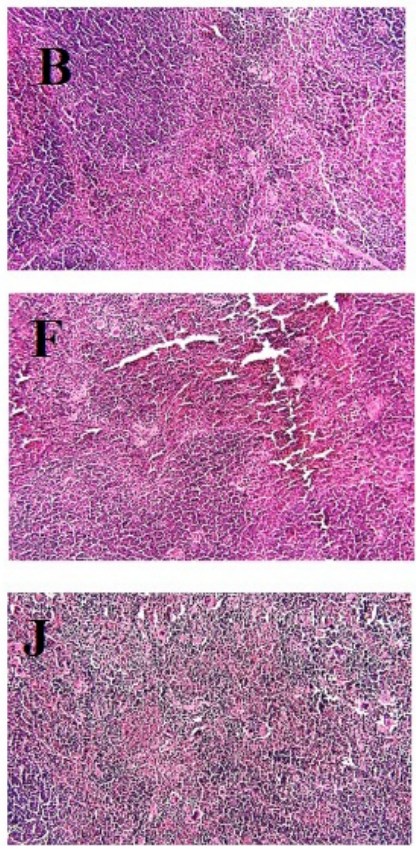
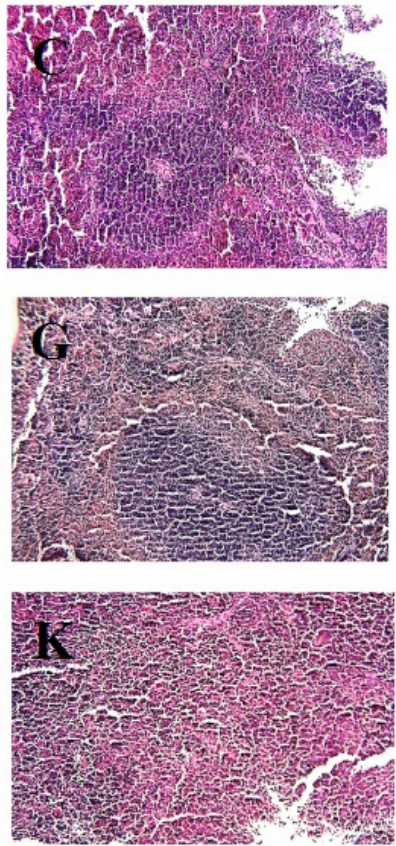
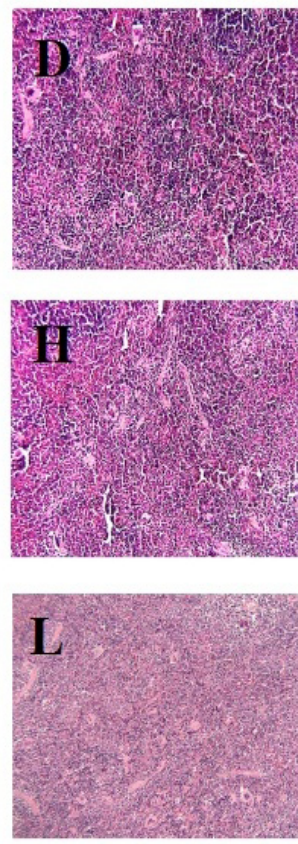

IMMUNoREGULATION

Figure 18. Pathologic complications observed in the spleen tissue of the mice receiving $10 \mathrm{mg} / \mathrm{kg}$ CEES at intervals from 12 hours to 7 months after contamination

(A) Note the normal appearance of the spleen tissue in the control group; (B) 12 hours after receiving CEES; the spleen tissue appears normal; (C) 24 hours after receiving CEES; note the mild decrease in the cell population of white pulp; (D) 1 week after receiving CEES; the mild activation of megakaryocytes is evident; (E) 2 weeks after receiving CEES; note the mild hyperemia; (F) 1 month after receiving CEES; note the slight reduction in the size of red pulp; (G) 2 months after receiving CEES: note the mild reduction in the white pulp size; $(\mathrm{H}) 3$ months after receiving CEES: necrotic changes in lymphocytes in the lower left side of the Figure is evident; (I) 4 months after receiving CEES; note the moderate reduction in the size of white and red pulps with necrotic changes in white pulp lymphocytes; (J) 5 months after receiving CEES; note the slight reduction in white pulp and necrotic changes in lymphocytes; (K) 6 months after receiving CEES: note the mild activation of megakaryocytes and moderate necrotic changes in lymphocytes; and (L) 7 months after receiving CEES: note the moderate infiltration of macrophages (H\&E, 100×).

term complications of SM contamination, IP administration of $6.35 \mathrm{mg} / \mathrm{kg}$ SM caused nausea, diarrhea, blindness, weight loss, intestinal necrosis, and damage to the spleen, and the animal stayed alive at least for 6 days. Histopathologically, the injection of SM into the perito- neum of BALB/c mice, followed by the IP injection of Sheep Red Blood Cells (S-RBC) led to the total depletion of the periarterial lymphatic sheath, widespread necrosis, loss of pale center, and atrophy in the mantle zone in the spleen of mice [3].
A

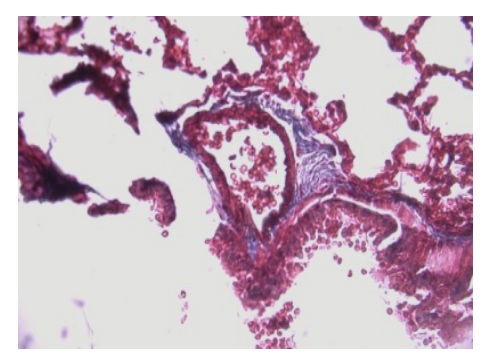

B

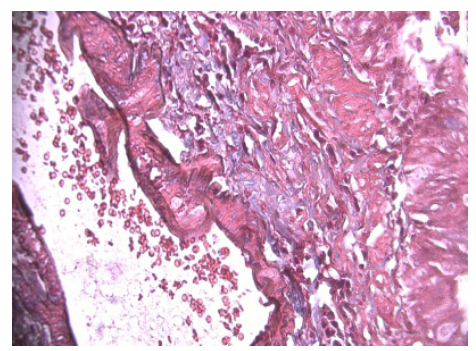

C

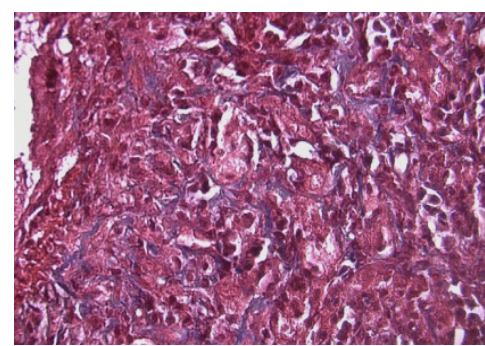

IMMUnoReguLation

Figure 19. Trichrome staining of lung tissues (Trichrome, 400X)

(A) In the control group, collagen fiber is present around vascular spaces; (B) Collagen diffusely is present in the parenchyma, around vascular spaces and airways in mice receiving $10 \mathrm{mg} / \mathrm{kg}$ CEES after 6 months; (C) Collagen fibers appear in the lung parenchyma among mice receiving $10 \mathrm{mg} / \mathrm{kg}$ CEES after 7 months. 
In 2005, Vijayaraghavan et al. examined the effect of SM by percutaneous, subcutaneous, per oral administration methods within 7 days in mice. The histopathological changes in the liver, lung, and spleen suggested that the liver had more significant changes, including the granulovacuolar degeneration of hepatocytes, cytoplasmic perinuclear clamping, and Kupffer cell hyperactivity. Hepatocytes of exposed mice to the SM revealed a moderate centrilobular necrosis/apoptosis along with the vacuolar degeneration of hepatocyte. In addition, the percutaneous method of administration had the greatest effect on the liver.

In the lung tissue, most of the lesions were observed in the parenchyma. Furthermore, the inflammation was due to the infiltration of neutrophils into the airways and alveoli. Congestion and pulmonary hemorrhage, as well as the granulovacuolar degeneration of bronchial lymph nodes, were fully apparent. Vascular congestion in the spleen tissue was an indicator of oxidative stress and the severity of the lesions depended on the method of SM administration. Moreover, the red pulp of spleen in the mice with percutaneous administration method was more congestive [15].

Zakeri and Karrari (2006) explored the effects of IP administration of $2.5,5$, and $10 \mathrm{mg} / \mathrm{kg}$ of SM on the liver tissue at 2 and 8 weeks later. They reported that $2.5 \mathrm{mg} /$ $\mathrm{kg} \mathrm{SM}$ after 8 weeks, as well as $5 \mathrm{mg} / \mathrm{kg}$ and $10 \mathrm{mg} / \mathrm{kg}$ after 2 and 8 weeks, respectively, caused the hyperemia of sinusoids, fading boundaries of cytoplasm, and hyperchromasia of the hepatocytes nucleus. In PAS staining, the glycogen levels in the recipients of $5 \mathrm{mg} / \mathrm{kg}$ and 10 $\mathrm{mg} / \mathrm{kg}$ decreased after 8 weeks [16].

Ahmadi and Akbari (2005) investigated the effect of $1270 \mathrm{mg} / \mathrm{mL}$ inhaled $\mathrm{SM}$ on the lung tissue of mice at 2, 4, and 6-month intervals. Their results following 2 months of administration of SM demonstrated negligible and invisible lesions. However, after 4 months, type 1 and type 2 pneumocystis hyperplasia were detected in the lungs, but no progressive lesions were observed. After 6 months, in addition to acute and chronic inflammation, the thickening of alveolar wall was also observed [9]. Another study report that in the lung of rats exposed to SM, histopathological evidence suggests the development of time- and dose-dependent bronchiolitis obliterans and pulmonary fibrosis [17]. However, they disregarded the long-term effects of SM.

Assessing the time intervals of resulted complications following IP administration of SM indicated that shortterm complications occur 12 hours after contamination with CEES. There are still pathological complications in 7-month follow-up which are not time-dependent. However, some complications such as weight loss and severe pathophysiological signs were not observed sooner than 3 months after the injection but occurred after 4 months. Thus, other investigators failed to report many of our observations.

Almost the same pattern of complications was observed in people exposed to SM. In addition, the onset of complications and development of hyperacute and acute signs occur, respectively after 6 hours and 6 weeks following exposure to SM. However, delayed complications appear over the years, which differ from the early symptoms in severity and type [18]. It can be concluded that the body, after acute response to this toxic substance, develops delayed complications in the long-term which are considered disabling complications among veterans. According to lifetime studies on mice and humans, every 4 months in the life of a mouse approximately equals to 21 years of human life [19]. Therefore, the present study was able to simulate the complications of exposure to SM in a timely manner. The aforementioned complications are consistent with human and can be fully used as an animal model for short- and long-term complications of SM exposure.

To evaluate the model with respect to side effects associated with other organs, the examination of ocular and skin complications and evaluation of pulmonary function in exposed animals are recommended. This developed model can also be used to investigate the mechanisms involved in such delayed complications at the molecular level to prevent and treat SM-induced complications.

To summerize, the obtained results indicate that IP injection of $10 \mathrm{mg} / \mathrm{kg}$ CEES in the herbal oil solvent to 8 to 6 weeks old BALB/c mice causes pathological changes in the short term (less than one month after the injection). It also results in clinical signs like weight loss, hair loss, and pathological signs such as parenchymal inflammation/fibrosis in the lung, distribution of lobular pattern in the liver, and white pulp hypocellularity in the spleen tissues in the long term (more than 6 months after the injection) in the animals exposed to SM. Thus, it can be used as an animal model of short- and long-term complications following exposure to SM.

\section{Ethical Considerations}

\section{Compliance with ethical guidelines}

The ethical issue of study was approved by the Research Ethics Committee of Shahed University (code: IR.SHAHED.REC 1394.79). 


\section{Funding}

The present study was supported by Immunoregulation Research Center of Shahed University and Iran's Department of Environment.

\section{Authors contributions}

\section{Authors contributions}

Conceptualization: Tooba Ghazanfari; Methodology: Tooba Ghazanfari, Susan Kaboudanian Ardestani, Mohammad Reza Vaez-Mahdavi, Reza Gharebaghi, Marjan Heshmati, Soghrat Faghihzadeh, Marziyeh Eghtedardoost; Labratory investigation: Marziyeh Eghtedardoost, Mohsen Varmazyar, Zahra Kianmehr; Clinical findings: Hasan Ghasemi; Pathological investigation: Reza Sedaghat; Statistical analysis: Soghrat Faghihzadeh, Mohammad Mehdi Naghizadeh; Writing-original draft: Marziye Eghtedar Doost, Fatemeh Heidari, Tooba Ghazanfari, Susan Kaboudanian Ardestani; Writing-review \& editing: Marziye Eghtedar Doost, Tooba Ghazanfari, Fateme Heidari, Susan Kaboudanian Ardestani; Resources: Marziye Eghtedar Doost, Tooba Ghazanfari, Susan Kaboudanian Ardestani; and Supervision: Tooba Ghazanfari.

\section{Conflict of interest}

The authors declared no conflict of interest.

\section{Acknowledgements}

We would like to thank Ms. Ensie Sadat Mirsharif for laboratory coordination and technical assistance.

\section{References}

[1] Khateri S, Ghanei M, Keshavarz S, Soroush M, Haines D. Incidence of lung, eye, and skin lesions as late complications in 34,000 Iranians with wartime exposure to mustard agent. Journal of Occupational and Environmental Medicine. 2003; 45(11):1136-43. [DOI:10.1097/01.jom.0000094993.20914.d1]

[2] Gould NS, White CW, Day BJ. A role for mitochondrial oxidative stress in Sulfur Mustard analog 2-Chloroethyl Ethyl Sulfide-induced lung cell injury and antioxidant protection. The Journal of Pharmacology and Experimental Therapeutics. 2009; 328(3):732-9. [DOI: 10.1124/jpet.108.145037] [PMID] [PMCID]

[3] Hassan ZM, Ebtekar M. Modeling for immunosuppression by Sulfur Mustard. International Immunopharmacology. 2001; 1(3):605-10. [DOI:10.1016/S1567-5769(00)00036-9]
[4] Malaviya R, Sunil VR, Cervelli J, Anderson DR, Holmes WW, Conti ML, et al. Inflammatory effects of inhaled Sulfur Mustard in rat lung. Toxicology and Applied Pharmacology. 2010; 248(2):89-99. [DOI:10.1016/j.taap.2010.07.018] [PMID] [PMCID]

[5] Mishra NC, Rir sima ah J, Grotendorst GR, Langley RJ, Singh SP, Gundavarapu S, et al. Inhalation of Sulfur Mustard causes long-term $\mathrm{T}$ cell-dependent inflammation: Possible role of Th17 cells in chronic lung pathology. International Immunopharmacology. 2012; 13(1):101-8. [DOI:10.1016/j. intimp.2012.03.010] [PMID] [PMCID]

[6] Joseph LB, Gerecke DR, Heck DE, Black AT, Sinko PJ, Cervelli JA, et al. Structural changes in the skin of hairless mice following exposure to Sulfur Mustard correlate with inflammation and DNA damage. Experimental and Molecular Pathology. 2011; 91(2):515-27. [DOI:10.1016/j. yexmp.2011.05.010] [PMID] [PMCID]

[7] McNutt P, Hamilton T, Nelson M, Adkins A, Swartz A, Lawrence $\mathrm{R}$, et al. Pathogenesis of acute and delayed corneal lesions after ocular exposure to Sulfur Mustard vapor. Cornea. 2012; 31(3):280-90. [DOI:10.1097/ICO.0B013E31823D02CD] [PMID]

[8] O'Neill HC, White CW, Veress LA, Hendry Hofer TB, Loader JE, Min E, et al. Treatment with the catalytic metalloporphyrin AEOL 10150 reduces inflammation and oxidative stress due to inhalation of Sulfur Mustard analog 2-Chloroethyl Ethyl Sulfide (CEES). Free Radical Biology \& Medicine. 2010 48(9):1188-96. [DOI: 10.1016/j.freeradbiomed.2010.01.039] [PMID] [PMCID]

[9] Ahmadi KA, Mohammad Hosseini Akbari H. [Effect of Sulfur Mustard on the rat lung (Persian)]. Journal of Military Medicine. 2005; 7(3):219-23.

[10] Poursaleh Z, Harandi AA, Vahedi E, Ghanei M. Treatment for Sulfur Mustard lung injuries: New therapeutic approaches from acute to chronic phase. DARU Journal of Pharmaceutical Sciences. 2012; 20(1):27. [DOI:10.1186/20082231-20-27] [PMID] [PMCID]

[11] The Comprehensive R Archive Network. R Network Software. London: The Comprehensive R Archive Network; 2018.

[12] Yang YC, Ward JR, Luteran T. Hydrolysis of mustard derivatives in aqueous acetone-water and ethanol-water mixtures. The Journal of Organic Chemistry. 1986; 51(14):2756-9. [DOI:10.1021/jo00364a025]

[13] Wiley-VCH. Polyethylene Glycol [MAK Value Documentation, 1998]. In: Wiley-VCH, editor. The Mak-Collection for Occupational Health and Safety. Weinheim: Wiley-VCH; 2002.

[14] Gautam A, Vijayaraghavan R, Sharma M, Ganesan K. Comparative toxicity studies of Sulfur Mustard (2, 2'-dichloro diethyl sulfide) and monofunctional Sulfur Mustard (2-Chloroethyl Ethyl Sulfide), administered through various routes in mice. Journal of Medical Chemical, Biological and Radiological Defense. 2006; 4:1-21.

[15] Vijayaraghavan R, Kulkarni A, Pant SC, Kumar P, Rao PV, Gupta N, et al. Differential toxicity of Sulfur Mustard administered through percutaneous, subcutaneous, and oral routes. Toxicology and Applied Pharmacology. 2005; 202(2):180-8. [DOI:10.1016/j.taap.2004.06.020] [PMID] 
[16] Zakerifard A, Ghahari L. [Chronic effects of mustard gas on liver parenchyma in rat (Persian)]. Annals of Military and Health Sciences Research. 2006; 4(1):725-8.

[17] McGraw MD, Dysart MM, Hendry Hofer TB, Houin PR, Rioux JS, Garlick RB, et al. Bronchiolitis obliterans and pulmonary fibrosis after Sulfur Mustard inhalation in rats. American Jurnal of Respiratory Cell and Molecular Biology. 2018; 58(6):696-705. [DOI:10.1165/rcmb.2017-0168OC] [PMID] [PMCID]

[18] Balali Mood M, Hefazi M. Comparison of early and late toxic effects of Sulfur Mustard in Iranian veterans. Basic \& Clinical Pharmacology \& Toxicology. 2006; 99(4):273-82. [DOI:10.1111/j.1742-7843.2006.pto_429.x] [PMID]

[19] Geifman N, Rubin E. The mouse age phenome knowledgebase and disease-specific inter-species age mapping. PLOS ONE; 8(12):e81114. [DOI:10.1371/journal.pone.0081114] [PMID] [PMCID] 